\title{
Executive Function in Very Preterm Children at Early School Age
}

\author{
Cornelieke S. H. Aarnoudse-Moens • Diana P. Smidts • \\ Jaap Oosterlaan • Hugo J. Duivenvoorden • \\ Nynke Weisglas-Kuperus
}

Published online: 2 June 2009

(C) The Author(s) 2009. This article is published with open access at Springerlink.com

\begin{abstract}
We examined whether very preterm ( $\leq 30$ weeks gestation) children at early school age have impairments in executive function (EF) independent of IQ and processing speed, and whether demographic and neonatal risk factors were associated with EF impairments. A consecutive sample of 50 children ( 27 boys and 23 girls) born very preterm (mean age $=5.9$ years, $S D=0.4$, mean gestational age $=28.0$ weeks, $S D=1.4$ ) was compared to a sample of 50 age-matched full-term controls (23 girls and 27 boys, mean age $=6.0$ years, $S D=0.6$ ) with respect to performance on a comprehensive EF battery, assessing the domains of inhibition, working memory, switching, verbal fluency, and concept generation. The very preterm group demonstrated poor performance compared to the controls on all EF domains, even after partialing out the effects of IQ. Processing speed was marginally related to EF. Analyses
\end{abstract}

C. S. H. Aarnoudse-Moens $(\square) \cdot N$. Weisglas-Kuperus

Department of Pediatrics, Division of Neonatology,

Erasmus University Medical Centre Sophia

Children's Hospital Rotterdam,

Room SP 3433, P.O. Box 2060, 3000 CB Rotterdam,

The Netherlands

e-mail: c.moens@erasmusmc.nl

D. P. Smidts $\cdot$ J. Oosterlaan

Department of Clinical Neuropsychology,

Vrije Universiteit Amsterdam,

Amsterdam, The Netherlands

H. J. Duivenvoorden

Department of Medical Psychology and Psychotherapy,

Erasmus University Medical Centre,

Rotterdam, The Netherlands with demographic and neonatal risk factors showed maternal education and gestational age to be related to EF. This study adds to the emerging body of literature showing that very preterm birth is associated with EF impairments.

Keywords Executive function · Very preterm · IQ ·

Speed of processing

Better perinatal and neonatal care has improved survival rates for very preterm ( $\leq 30$ weeks gestation) children. However, the developmental outcome of these children at later age is of significant concern (Aylward 2005). Such outcomes include poor cognitive function, learning difficulties, and behavior problems such as Attention-Deficit/ Hyperactivity Disorder (AD/HD) (Bhutta et al. 2002; Botting et al. 1997; Wolke and Meyer 1999), which may result in school difficulties and the need for special assistance and special education (Hille et al. 1994; Stjernqvist and Svenningsen 1999). Early identification of and better insight into these learning and behavioral problems would aid early intervention.

Executive function (EF) refers to a set of neurocognitive processes that are important for behavioral and cognitive regulation, and include inhibition, working memory, cognitive flexibility, goal selection, planning, and organization. Recent research has shown that learning difficulties and behavioral problems are both associated with deficits in executive function (Lezak et al. 2004; Mazzocco and Kover 2007; Pennington and Ozonoff 1996; Powell and Voeller 2004). For example, deficits in inhibition, working memory and cognitive flexibility have been strongly associated with mathematical difficulties in children with a normal IQ (Bull and Scerif 2001). Difficulties in reading and writing skills have been related to working memory and inhibitory control deficits (Altemeier et al. 2006; Brosnan et al. 
2002; Rucklidge and Tannock 2002; van der Schoot et al. 2000). Executive dysfunction has also been demonstrated in a range of behavioral problems (Nigg 2005; Pennington and Ozonoff 1996; Russell 1997). Barkley (1997) for example, has proposed that $\mathrm{AD} / \mathrm{HD}$ arises from a deficit in inhibition, that in turn results in secondary EF deficits, such as impaired working memory.

A growing body of research is documenting that very preterm children show deficits in EF, including inhibitory control, working memory, verbal fluency, planning, switching or set-shifting, and attention (e.g., Allin et al. 2008; Anderson and Doyle 2004; Bayless and Stevenson 2007; Bohm et al. 2004; Edgin et al. 2008; Kulseng et al. 2006; Marlow et al. 2007; Narberhaus et al. 2008; Rushe et al. 2001; Saavalainen et al. 2007; Shum et al. 2008; Taylor et al. 2006). However, studies differ greatly in terms of their findings, measures employed, and age at assessment. Some studies have focused on isolated aspects of EF (e.g., Allin et al. 2008; Harvey et al. 1999). By employing a more comprehensive assessment, others demonstrated that executive dysfunction in very preterm children is a pervasive deficit that pertains to all domains of EF (e.g., Anderson and Doyle 2004; Bohm et al. 2004), rather than comprising a pattern of strengths and weaknesses in EF. In terms of age groups, a range of researchers has examined EF in toddlers (e.g., Matthews et al. 1996), while others have focused on EF in very preterm young adults (Allin et al. 2008; Nosarti et al. 2007; Saavalainen et al. 2007). At early school age, which is the focus of the present study, some EF domains have been assessed extensively (e.g., inhibitory control), while others, such as cognitive flexibility and verbal fluency have received little attention. In addition, conceptual reasoning skills have not been examined at all in very preterm children at early school age. The present study was conducted to add to the limited literature targeting a broad range of EFs in very preterm children at early school age.

There is debate on the extent of overlap between the concepts of EF and IQ (Ardila et al. 2000). Some authors suggest that there is a substantial overlap (Duncan et al. 1996), others consider IQ and EF to be related yet distinct (Barnes and Dennis 1998; Friedman et al. 2006; Friedman et al. 2007; Welsh et al. 1991). The extent of overlap may depend on the type of EF (Arffa 2007). For example, setshifting does not appear to be related to IQ (Friedman et al. 2006; Friedman et al. 2007), while verbal fluency (Ardila et al. 2000), conceptual problem solving and cognitive efficiency, may be strongly related to IQ (Seidenberg et al. 1983). In addition, failure on IQ tests might be caused by impaired executive processes (Duncan et al. 1996), an issue only a few studies have addressed in very preterm children. In order to better understand the nature of the neurocognitive weaknesses that very preterm children encounter at early school age, it is necessary to disentangle the relationship of IQ and EF in these children.

Inhibitory control (Christ et al. 2003) and switching tasks (Salthouse et al. 1998) have been suggested to rely greatly on processing speed. "Lower-order" cognitive processes, such as processing speed, have been proposed to underlie "higher-order" processes such as EF (Demetriou et al. 2002; Kail 1991; Sergeant 2000), as white matter tracts are involved in processing information across different brain areas to establish various neuropsychological functions (Charlton et al. 2006). In very preterm children, white matter tract abnormalities have been reported (Anjari et al. 2007), which possibly result in slow speed of processing. Because a number of studies have reported slow speed of processing in very preterm children (Anderson and Doyle 2003; Christ et al. 2003; Rose et al. 2002), it has been questioned whether the EF deficits in very preterm children can be reduced to slower-than-average speed of processing (Luciana et al. 1999; Rose et al. 2002). So far, research has not examined the potential contribution made by slower processing speed to deficits in EF in very preterm children.

At last, our knowledge of the effect of demographic and neonatal risk factors on EF in very preterm children is limited. Knowing whether specific factors increase or rather decrease the impairments is essential for early intervention. While lower IQ scores and behavioral problems have been frequently associated with neonatal risk factors such as intraventricular hemorrhage (IVH), periventricular leukomalacia (PVL), chronic lung disease or sociodemographic disadvantage (Klebanov et al. 1994; Weisglas-Kuperus et al. 1993; Whitaker et al. 1997), the unique contributions of demographic and neonatal risk factors to variations in EF in very preterm children remain unclear.

The primary aim of this study was to examine EF in a consecutive sample of very preterm children at early school age. We compared their performance on a comprehensive EF battery, assessing the domains inhibition, working memory, switching, verbal fluency and concept generation, to that of an age-matched, full-term control group. On the basis of the existing literature, we expected that the very preterm group would underperform the controls in all domains assessed. Our second aim was to explore whether deficits in EF (in particular inhibition and switching) could be explained by processing speed. Next, we examined group differences in EF while controlling for IQ and vice versa. We hypothesized that the EF impairments in the very preterm group would remain existent after controlling for IQ. Finally, we examined the relationship between various demographic as well as neonatal risk factors and EF. It was hypothesized that a higher level of demographic and neonatal risk would be associated with poorer performance on the EF tasks. 


\section{Method}

Participants

The study group consisted of 50 children born very preterm (i.e., gestational age $\leq 30$ weeks, established by weeks and days after the mother's last menstrual period), and 50 controls. For the purposes of the current study, our very preterm sample was consecutively and randomly acquired from the total population of very preterm survivors $(N=276)$ born and admitted between 1998-1999 to the neonatal intensive care unit (NICU) of the Sophia Children's Hospital Rotterdam. Our sample did not differ from the total population of very preterm survivors in terms of gender, $\chi^{2}(1,115)=1.15, p=$ 0.30 ; gestational age, $F(1,113)=1.16, p=0.24$; birthweight, $F(1,113)=.96, p=0.33$; days of ventilation, $F(1,113)=0.04$, $p=0.84$; days of added oxygen, $F(1,113)=0.34, p=0.54$; or days of intensive care, $F(1,113)=0.28, p=0.66$. The control group (mean gestational age $=39.7, S D=1.3$; mean birthweight $=3579, S D=510$ ) was recruited from local elementary schools as a part of a normative study of the VU University Amsterdam. Included in the control group were normally developing children without histories of prematurity (i.e., gestational age $>37$ weeks), perinatal complications, psychiatric and neurological disorders. Exclusion criteria for both groups were mental and/or motor handicaps too profound to allow task execution. Written informed consent was obtained from all parents of the participating children. The study was approved by the Erasmus Medical Centre medical-ethical review board.

Table 1 presents the sample characteristics of the very preterm and the control group. No significant group differences were found for age, level of maternal education, or for the distribution of both genders. Very preterm children obtained lower IQ scores $(F(1,98)=20.2, p<$ $0.001)$, and comprised of more twins and triplets $\left(\chi^{2}(1\right.$, $100)=29.9, p<0.001)$, than the controls. Visual and hearing impairments were classified according to Wood et al. (2000). Cerebral palsy was classified according to standards of the Surveillance of Cerebral Palsy in Europe (SCPE). The SCPE standards (2000) differentiate between spastic (unilateral or bilateral), ataxic and dyskinetic (dystonic or choreo-athetotic) CP. Thirteen (26\%) very preterm children had neurosensory impairments (eight with visual impairment, two with hearing impairment, one with cerebral palsy, and one with both cerebral palsy as well as with visual impairment). Visual and hearing impairments, and CP, are hereafter referred to as neurosensory impairments. Three $(6 \%)$ very preterm children were formally diagnosed with Pervasive Developmental Disorder Not Otherwise Specified (PDD-NOS), of whom two participated in special education. None of the children in the control group had neurosensory impairments.

Table 2 presents the neonatal characteristics of the very preterm group. The severity of neonatal illness is expressed

Table 1 Sample Characteristics of the Very Preterm and the Control Group

\begin{tabular}{|c|c|c|}
\hline Sample Characteristics & Very Preterm & Control \\
\hline Age (in years), mean $(S D)$ & $5.9(.4)$ & $6.0(.6)$ \\
\hline Level of maternal education, mean $(S D)$ & $3.9(.9)$ & $4.2(.8)$ \\
\hline $\mathrm{IQ}$, mean ( $S D$, range) & $92.5(17.5,70-140)$ & $109.0(19.2,71-150)^{* * *}$ \\
\hline Boys, $n(\%)$ & $27(54.0)$ & $23(46.0)$ \\
\hline Twins or triplets, $n(\%)$ & $11(22.0)$ & $0(0.0)^{* * *}$ \\
\hline \multicolumn{3}{|l|}{ Visual impairment } \\
\hline Impaired, use of glasses, $n(\%)$ & $9(18.0)$ & $0(0.0)^{* * *}$ \\
\hline Blind or perceives light only, $n(\%)$ & $0(0.0)$ & $0(0.0)$ \\
\hline \multicolumn{3}{|l|}{ Hearing impairment } \\
\hline Impaired, use of hearing aid, $n(\%)$ & $2(4.0)$ & $0(0.0)$ \\
\hline Deafness, $n(\%)$ & $0(0.0)$ & $0(0.0)$ \\
\hline \multicolumn{3}{|l|}{ Cerebral Palsy } \\
\hline Spastic (unilateral), $n(\%)$ & $3(6.0)$ & $0(0.0)$ \\
\hline Ataxic, $n(\%)$ & $0(0.0)$ & $0(0.0)$ \\
\hline Dyskinetic, $n(\%)$ & $0(0.0)$ & $0(0.0)$ \\
\hline
\end{tabular}

Level of maternal education: 1 and 2 = primary education/secondary education not finished; 3 = secondary education; $4=$ intermediate vocational education; $5=$ higher vocational education; 6 and $7=$ university (Central Office of Statistics 2004).

$* p<0.05$.

$* * p<0.01$.

$* * * p<0.001$. 
Table 2 Neonatal Characteristics of the Very Preterm Group

\begin{tabular}{lc}
\hline $\begin{array}{l}\text { Neonatal Characteristics } \\
\text { Birthweight in grams, mean }\end{array}$ & $1042.6(31.8,605.0-1640.0)$ \\
$\quad(S D$, range $)$ & $28.0(1.4,25.0-30.0)$ \\
Gestational age in weeks, mean & $78.7(22.9)$ \\
$\quad(S D$, range $)$ & \\
Duration of NICU stay in days, & $3.0(6.0)$ \\
mean $(S D)$ & $23.0(46.0)$ \\
$<750$ g birthweight, $n(\%)$ & $4.0(8.0)$ \\
$<28$ weeks gestational age, $n(\%)$ & $5.0(84.0)$ \\
Outborn, $n(\%)$ & $11.0(22.0)$ \\
Assisted ventilation, $n(\%)$ & $0.0(0.0)$ \\
Grade I/II Intra ventricular & \\
hemorrhage, $n(\%)$ & $2.0(4.0)$ \\
Grade III/IV Intra ventricular & $0.0(0.0)$ \\
hemorrhage, $n(\%)$ & $2.0(4.0)$ \\
Periventricular Leukomalacia, $n(\%)$ & $0.0(0.0)$ \\
Hypoglycemia, $n(\%)$ & $27.0(54.0)$ \\
Meningitis, $n(\%)$ & $7.0 / 8.0 / 1.0(14.0 / 16.0 / 2.0)$ \\
Necrotizing enterocolitis, $n(\%)$ & $3.0(6.0)$ \\
Chronic lung disease, $n(\%)$ & $3.5(.9)$ \\
ROP (Grade I/II/III), $n(\%)$ & \\
Small for gestational age, $n(\%)$ & \\
Neurobiological risk score ${ }^{\mathrm{a}}$, & \\
mean $(S D)$ &
\end{tabular}

Outborn refers to infants born in community hospitals and referred to the perinatal center for neonatal intensive care. Chronic lung disease is defined as oxygen dependence at 36 weeks corrected age. Small for gestational age is defined as birthweight less than the 3rd percentile for gestational age (Usher and McLean 1969).

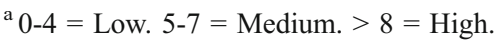

in the Neurobiological Risk Score (NBRS) total score (Brazy et al. 1991). The NBRS total score is a composite measure of neonatal risk that summarizes neonatal medical events, with higher scores indicating higher degree of neurobiological risk.

\section{Measures}

Go/NoGo The Go/NoGo task is a well-established measure of inhibition with adequate psychometric properties (Casey et al. 1997; Drewe 1975; Picton et al. 2007). In this study an adaptation of the original Go/NoGo paradigm was used (Smidts 2003), which has previously been employed by Raaijmakers et al. (2008). Children completed a Go/NoGo task in which images of an elephant or a dog appeared on a computer screen. Children were instructed to respond to the elephant (Go-stimulus) and to withhold their response when the dog appeared (NoGo-stimulus). Each trial began with a $200 \mathrm{~ms}$ fixation cross on the screen. After a $300 \mathrm{~ms}$ delay, the Go- or NoGo-stimulus was presented for $1000 \mathrm{~ms}$, with a fixed interstimulus interval of $1500 \mathrm{~ms}$. A fixed interstimulus interval was used as variable intervals (specifically shorter ones) would have made the task too difficult for the youngest children. Fifty percent of trials were Go-trials, and the trials were shown in a random order. After an initial practice block of 12 stimuli, where the child was required to respond correctly to at least 5 consecutive stimuli in order to proceed to the experimental trials, an experimental block consisting of 24 stimuli was completed. The total number of correct responses and efficiency of responding (total number of correct responses divided by the mean reaction time of correct responses) was used as an index of inhibition. Measures of efficiency have been used in previous studies on EF performance in preschoolers (Espy 1997; Isquith et al. 2005). Efficiency measures comprise both accuracy and response time and take into account Speed Accuracy Trade Off (SATO). As response time improves significantly during early childhood, the use of efficiency measures is valuable specifically in studies with young children.

The Shape School The original Shape School task is a storybook for preschoolers, designed to measure inhibition and switching processes (Espy 1997). Adequate psychometric properties have been established for the Shape School task (Espy et al. 2006). In the current study, we used a computerized, modified version of the Shape School (Smidts and Groot 2005). Children were asked to respond using response buttons (see Procedure for details regarding the response buttons). Children responded by pressing either the red or yellow button, depending on the color of the figure and the rule accompanying the condition. Three conditions were administered: the control, inhibition, and switching condition. In the control condition, the child was asked to respond to the color of the figures by pressing the corresponding button as quickly as possible. In the inhibition condition, children had to respond whenever they saw a figure with a happy face (fifty percent of the trials were inhibitory trials), but were instructed to suppress a response whenever they saw a figure with a sad face. In the switching condition, children had to give an opposite response (switch) by pressing the button that was originally linked with the other color whenever the figure was wearing a hat (fifty percent of the trials were switch trials). All conditions started with an initial practice block of 12 stimuli, where the child was required to respond correctly to at least 5 consecutive stimuli in order to proceed to the experimental trials, after which an experimental block consisting of 24 stimuli was completed. Trials were randomized within each condition. Stimuli were preceded by a $200 \mathrm{~ms}$ fixation cross and a $300 \mathrm{~ms}$ delay, and were presented for $2000 \mathrm{~ms}$ in condition $\mathrm{A}$ and $\mathrm{B}$, and for $3000 \mathrm{~ms}$ in condition $C$, with a fixed interstimulus interval of $1500 \mathrm{~ms}$. Dependent variables used in this study were: mean reaction time (RT) in ms on all trials from the control condition 
(measure for speed of processing); and the total number of correct responses and efficiency of responding (i.e., total number of correct responses divided by mean RT of correct responses) from the inhibition and switching conditions.

Day-Night Task The Day-Night task is a well-validated measure of prepotent response inhibition in young children (Diamond et al. 2002; Gerstadt et al. 1994; Simpson and Riggs 2005). In the Day-Night task (Gerstadt et al. 1994), children were shown a set of 16 cards with pictures of either a sun or a moon with stars. There were two conditions: (1) a control condition, in which the child had to say "day" in response to a sun card and "night" in response to a moon card, and (2) an experimental condition, where the child was asked to respond to the sun card by saying "night" and vice versa. In both conditions, the same set of cards was used, shown in a pseudorandom order. Response time for each condition for the total of 16 cards was recorded manually using a stopwatch. The dependent variables used in this study were the total number of correct responses and the efficiency of responding in the control condition and experimental condition (i.e., total number of correct responses divided by the total naming time).

Verbal Fluency In this Verbal Fluency task (Welsh et al. 1991), children were asked to name as many examples from two specific categories: "animals" and "things you can eat or drink" within a 40-second time frame. Two examples of each category were provided before the beginning of the task. An item named for the second time was scored as incorrect, as well as examples that fell outside abovementioned categories. The total number of correct words across both categories was used as an index for verbal fluency.

Word Span This task, based on the Digit Span subtest of the Wechsler IQ Scale for Children (WISC: Wechsler 1997), was used to assess verbal working memory (Smidts 2003). A string of words was read aloud, and the child was asked to repeat the words. Similar to the WISC subtest, the number of words increased across trials, to a maximum of six words. There were two strings of words within each trial. The child had to repeat at least one string correctly in order to proceed to the next trial. In the forward condition, words had to be repeated in the same order as read by the examiner, and in the backward condition, words were to be repeated in the reverse order. The dependent variables used in this study were the total number of correctly recalled strings in the forward and backward condition, of which the latter served as an index for working memory.

Object Classification Task for Children (OCTC) The original Object Classification Task for Children (Smidts et al. 2004) is a concept-shifting task that requires the child to group six toys according to three predetermined groupings: color (red or yellow), size (big or small), and function (car or plane). In this study, as opposed to toys, we used cards. These cards depicted yellow or red cars or planes, and could be sorted according to the same predetermined groupings as the toys in the original task. There were three conditions characterized by three increasing levels of structure in terms of help supplied by the examiner: (1) Free generation, where the child is required to sort the cards without any help of the examiner, (2) Identification, where the examiner constructs a category and the child is asked to identify the sort, and (3) Explicit cueing, where the child is explicitly told how to sort the cards. These different conditions will be explained below. First, there were two practice trials, where the child was asked to sort four cards depicting two different Disney figures (two cards showed identical pictures of Mickey Mouse, the other pair contained images of Donald Duck). The child was asked to "put the ones that are the same on this side of the table and the other ones that are the same on the other side of the table". These practice trials were designed to assess whether a child was able to sort according to overall appearance.

After these practice trials, the experimental trials started with presenting six cards to the child. In contrast to the practice trials, these cards did not show identical images that needed to be matched, but instead the child was required to sort the cards according to color (three cards showed red images, the other three cards displayed images in yellow), size (three cards depicted small images, the other three images were large), or function (three cards displayed cars, the other three had planes on them). The child was told, "there is something the same about these images", and was then asked to put the ones that are the same on this side of the table and the other ones that are the same on the other side of the table". After a correct sort of one of the three groupings (i.e., color, size or function), the child was encouraged to verbally name the identified grouping "So why did you place these cards on this side of the table and the other ones over there? What's the same about these pictures?". The child's answer was recorded and the examiner then mixed up the cards and asked the child to "make two groups again, but this time, something else has to be the same". This procedure was repeated until the child had correctly sorted the cards according to the three different groupings. For each correct sort, the child received 3 points. In addition, one point was given for each correct verbally named grouping. The maximum score which could be received was 12 points. If the child had arranged the cards correctly according to color, size or function, but was unable to sort the cards again for a second (or third) time, the examiner sorted the cards according to 
one of the remaining categories. The child was then asked to identify the sort ("So can you tell me what's the same about these cards?"). This is called the Identification condition. If the child answered correctly, a score of 2 points were given. If the child was unable to identify the sort, the examiner specifically asked the child to sort the cards according to a particular grouping ("Can you put all the red ones over there, and all the yellow ones over there?"). This was called the Explicit cueing condition, where the child received one point for each correct sort. However, if the child did not understand task instructions when first presented with the six cards, one dimension was removed, and the child was shown four cards, which could be sorted according to either color or size. Testing procedures and point scoring system were similar to those described for the six cards. The total raw score was calculated by summing all the points earned and was used as an indication of childrens' ability to shift between concepts.

Intelligence Four subtests of the Wechsler Primary and Preschool Scale Intelligence-Revised (Wechsler 1997; Dutch version by Vander Steene and Bos 1997) were used to estimate full scale IQ: Picture Completion, Vocabulary, Block Design and Similarities. The Vocabulary and Similarities (Verbal Scale) subtest scores were added up, and then multiplied by three. The same procedure was followed for the Picture Completion and Block Design subtests (Performance Scale). Both the Verbal and Performance Scale scores were then added up into a composite score, of which the corresponding full scale IQ could be derived from the manual (Sattler 1992). Scores on these subtests correlate highly ( 0.90 range) with full scale IQ (Groth-Marnat 1997).

\section{Procedure}

Specifically trained experimenters administered all measures using standardized instructions. To control for order effects, measures were administered in two different orders. Half of the children in each group performed the tasks according to order A (Intelligence subtests - Day-Night task - Go/NoGo - OCTC - Shape School control condition and inhibition condition - Verbal Fluency Shape School switching condition - Word Span), while the other half of the children of in each group performed the tests according to order B (Intelligence subtests - Go/ NoGo - Word Span - Shape School control condition and inhibition condition - Verbal Fluency - Shape School switching condition - OCTC - Day-Night task). Computerized tasks were administered using the E-Prime software package (Psychology Software Tools, Pittsburgh, PA) and a Dell Latitude D800 laptop with a 15.4-inch color screen. Two response buttons were placed right in front of the laptop. Children responded by making a button press with one hand, but were required to keep both hands placed on top of the buttons so that they could react as quickly as possible. The buttons were converted emergency stop switches, with an external diameter of $94 \mathrm{~mm}$ (MOELLER Safety Products; model number: FAK-R/V/KC11/1Y). The stimuli were 700 pixels high and 500 pixels in width and presented with a $45^{\circ}$ visual angle. Total duration of testing was ninety minutes, and frequent breaks were introduced to avoid fatigue. The children were examined individually in a quiet room while one of their parents was present.

\section{Statistical Analyses}

The observations in this study were not strictly independent, given the large number of multiple births. Therefore, we applied the method of mixed modeling, i.e., random regression modeling (RRM), to take the relatedness of the multiple births into account. The error structure was assumed to be related (compound symmetry) which implies that both correlations and variances within the multiple births did not differ significantly.

Group differences for the EF task dependent variables were analyzed with group (very preterm versus control) as the between subjects factor. We also examined group differences both with and without controlling for maternal education, and both with and without inclusion of the subset of very preterm children with neurosensory impairments. Chi-square statistics were carried out to determine if there were group differences in rates of EF impairments. An impairment in EF was defined by a mean score on the EF dependent variable greater than one $S D$ below the control group mean (e.g., Taylor et al. 2006).

To examine the task specific impact of baseline processing speed, analyses were run while controlling for mean RT on the control condition of each specific task. Thus, group differences in performance on the Go/NoGo task and the Shape School inhibition and switching conditions (both tasks parallel in main task characteristics) were reanalyzed while entering the mean RT on the Shape School control condition as a covariate. Similar analyses were performed for the DayNight task experimental condition, with mean RT on the DayNight task control condition serving as a covariate.

Pearson's correlation coefficients were calculated for the relationship between IQ and the EF dependent variables. Cohen's guidelines were followed to indicate the strength of the correlation coefficients, with $0.10,0.30$, and 0.50 referring to small, medium, and large coefficients, respectively (Cohen 1992).

Next, group differences in EF were reanalyzed with IQ as a covariate, and vice versa. In addition, effect sizes in terms of Cohen's $d$ are provided. Cohen's guidelines were 
followed to indicate the strength of effect sizes, with 0.20 , 0.50 , and 0.80 referring to small, medium, and large effect sizes, respectively (Cohen 1992).

Hierarchical, multiple regression analyses were conducted to test the impact of demographic and neonatal variables on the EF dependent variables of the very preterm group. The demographic predictor variables gender and maternal education were entered in the first block, gestational age in the next block to examine the impact of gestational age over and above background demographics, and finally the NBRS total score as an index of neonatal illness was entered in the last block. For all analyses, the threshold for significance was set at $p<0.05$ (two-sided).

Missing Data and Extreme Values Missing data resulted from either examiner error or child noncompliance and was less than $4 \%$ for each of the dependent variables. Due to not pressing the response button hard enough, the percentage of missing data for the dependent variables of the Go/NoGo task was $9 \%$. Missing data was replaced by means of Expectation Maximization (Tabachnick and Fidell 2001). Analyses with and without replaced missing data revealed similar results. Extreme values were defined as having an absolute $z$-score exceeding $3 S D$ s from the group mean and identified in both groups separately. If an extreme value occurred due to examiner error $(n=1)$, the case was removed from the analyses. If due to child non-compliance $(n=1)$, the extreme value was truncated to either $0.5 \mathrm{SD}$ beyond the next most extreme score if that score was $z<3.0$ (Nigg et al. 2002). Extreme values due to either excellent or poor test performance remained unchanged.

\section{Results}

Convergent and Divergent Validity Coefficients The convergent validity coefficient for the two measures of processing speed in the current study (mean RT on the Shape School control condition and mean RT on the DayNight task control condition) was $.45, p<0.01$. Convergent validity coefficients between the inhibitory control tasks ranged from 0.22 to 0.58 , all $p s<0.001$. For each of the other measured EF domains, i.e., working memory, switching, verbal fluency and concept generation, we have employed one task per domain. Therefore, convergent validity coefficients could not be calculated for these measures. Divergent validity coefficients between the EF measures employed ranged from 0.15 to 0.39 , all $p \mathrm{~s}<0.001$ (details are available from first author).

EF Task Performance All participating children met the performance criteria for continuing on to the experimental trials during the practice phases of the Go/GoNo task and the Shape School task. Table 3 shows the means and standard deviations, and the statistical values indicating whether group differences were significant for the EF dependent variables. The very preterm group performed significantly poorer than the controls on all EF measures, except for the total number of correct responses and efficiency on the Shape School inhibition condition, or for total correct for the Word Span forward, for which group differences were nonsignificant. Controlling for maternal education did not alter these findings. Analyses with and without inclusion of the subset of very preterm children with neurosensory impairments, or with and without inclusion of the three very preterm children with PDDNOS revealed similar results. ${ }^{1}$

Table 4 depicts the rates of EF impairments in the very preterm group and control group. In comparison to the control group, very preterm children exhibited significant impairments in all measured EFs, except for the Shape School inhibition condition, or Verbal Fluency for which group differences in impairment rates were not significant, all $\chi^{2}(1, N=100)<2.10, p>0.05$.

Speed of Processing and IQ To determine the impact of baseline processing speed on the results, we reanalyzed group differences for efficiency on the Go/NoGo task and the Shape School inhibition and switching conditions while covarying for mean RT on the Shape School control condition (as a baseline measure of processing speed). Table 3 presents the results of these analyses. Group differences for the Go/NoGo task remained significant after taking into account processing speed. Group differences for the Shape School switching condition, however, became nonsignificant after covarying for processing speed. Group differences for efficiency on the Day-Night task experimental condition were adjusted for mean RT on the DayNight task control condition. Group differences remained significant.

Next, we examined the impact of IQ. Correlation coefficients between IQ and the EF dependent variables ranged from .13 to .46. Strong, nearly large (Cohen 1992) correlation coefficients were found for Word Span backwards $(r=0.43, p<0.01)$, OCTC total points $(r=0.44, p<$ $0.001)$, and efficiency on the Day-Night task experimental condition $(r=0.46, p<0.001)$. The majority of the EF group differences remained significant after controlling for IQ, except for the Shape School inhibition and switching conditions, for which group differences became nonsignificant. Table 3 presents the results of these analyses. Additional, exploratory analyses were conducted to exam-

\footnotetext{
${ }^{1}$ Full results are available from the first author upon request.
} 
Table 3 Means and Standard Deviations of the Dependent Variables, and Statistical Values Indicating Group Differences Between the Very Preterm and the Control Group

\begin{tabular}{|c|c|c|c|c|c|c|c|c|c|c|c|c|c|}
\hline \multirow[b]{3}{*}{ Dependent Variables } & & & & & & & & \multirow{2}{*}{\multicolumn{3}{|c|}{$\frac{\text { After Controlling for }}{\text { Processing Speed }^{\mathrm{a}}}$}} & \multirow{2}{*}{\multicolumn{3}{|c|}{$\begin{array}{l}\text { After Controlling for } \\
\text { IQ }\end{array}$}} \\
\hline & \multicolumn{2}{|c|}{ Very Preterm } & \multicolumn{2}{|l|}{ Control } & \multicolumn{3}{|l|}{ Group } & & & & & & \\
\hline & $M$ & $S D$ & $M$ & $S D$ & $F^{b}$ & $p$ & $d$ & $F^{b}$ & $p$ & $d$ & $F^{c}$ & $p$ & $d$ \\
\hline SS Control time in $\mathrm{ms}$ & 908 & 254 & 753 & 167 & 13.54 & $<0.01$ & 0.74 & - & - & - & 9.06 & $<0.01$ & 0.61 \\
\hline $\begin{array}{r}\text { SS Inhibition } \\
\text { total correct }\end{array}$ & 21.30 & 0.63 & 22.54 & 0.22 & 2.36 & 0.15 & 0.31 & 0.94 & 0.35 & 0.20 & 0.57 & 0.46 & 0.15 \\
\hline SS Inhibition efficiency & 0.02 & 0.01 & 0.02 & 0.01 & 0.73 & 0.41 & 0.17 & 2.87 & 0.11 & 0.34 & 2.38 & 0.15 & 0.31 \\
\hline $\begin{array}{r}\text { SS Switching } \\
\text { total correct }\end{array}$ & 18.84 & 0.73 & 22.22 & 0.28 & 7.66 & 0.02 & 0.56 & 3.15 & 0.10 & 0.13 & 1.83 & 0.20 & 0.27 \\
\hline $\begin{array}{l}\text { SS Switching } \\
\text { efficiency }\end{array}$ & 0.01 & $<0.01$ & 0.02 & $<0.01$ & 4.29 & 0.04 & 0.42 & 0.04 & 0.84 & 0.04 & 0.00 & 0.97 & 0.01 \\
\hline Go/NoGo total correct & 20.80 & 0.57 & 22.60 & 0.39 & 7.98 & 0.02 & 0.57 & 4.62 & $<0.05$ & 0.19 & 3.24 & 0.09 & 0.36 \\
\hline Go/NoGo efficiency & 0.03 & 0.01 & 0.04 & 0.01 & 16.92 & $<0.01$ & 0.83 & 5.32 & 0.04 & 0.47 & 6.28 & 0.03 & 0.51 \\
\hline DN Exp total correct & 13.15 & 0.37 & 14.40 & 0.23 & 7.40 & 0.02 & 0.55 & 1.04 & 0.33 & 0.21 & 0.86 & 0.37 & 0.19 \\
\hline DN Exp efficiency & 0.41 & 0.10 & 0.62 & 0.20 & 44.88 & $<0.001$ & 1.35 & 18.85 & $<0.01$ & 0.88 & 15.26 & $<0.01$ & 0.79 \\
\hline VF total correct & 11.87 & 3.71 & 14.90 & 5.21 & 10.86 & $<0.01$ & 0.67 & - & - & - & 5.40 & 0.02 & .47 \\
\hline $\begin{array}{l}\text { WS total correct } \\
\text { forwards }\end{array}$ & 5.30 & 0.23 & 5.84 & 0.17 & 3.77 & 0.07 & 0.39 & - & - & - & 0.97 & 0.34 & 0.20 \\
\hline $\begin{array}{l}\text { WS total correct } \\
\text { backwards }\end{array}$ & 1.90 & 0.69 & 2.76 & 0.87 & 15.61 & $<0.01$ & 0.80 & - & - & - & 6.90 & 0.02 & 0.53 \\
\hline OCTC total points & 7.32 & 2.10 & 8.80 & 2.01 & 14.69 & $<0.01$ & 0.77 & - & - & - & 4.78 & 0.04 & 0.44 \\
\hline
\end{tabular}

DN Exp = Day-Night task experimental condition, OCTC $=$ Object Classification Task for Children, SS Control = Shape School control condition, SS Inhibition $=$ Shape School inhibition condition, SS Switching $=$ Shape School switching condition, VF $=$ Verbal Fluency, WS $=$ Word Span.

${ }^{a}$ Processing speed is measured by the mean RT on the Shape School control condition.

${ }^{b} \mathrm{df}=1,98$.

${ }^{\mathrm{c}} \mathrm{df}=1,97$.

ine whether group differences in IQ between the very preterm children and the controls persisted while controlling for EF. For the purpose of this analysis, we extracted a composite $\mathrm{EF}$ factor from eight $\mathrm{EF}$ dependent variables (i.e., total number of correct responses for each task) using Principal Components Analysis. One variable of each task was chosen to prevent an artificial clustering of variables from the same task. An unrotated covariance matrix revealed one factor with an eigenvalue greater than 1, which explained $49 \%$ of the variance. The factor loadings of the EF dependent variables ranged between .38 and .90. Group differences for IQ remained significant after entering the EF factor as covariate, $F(1,97)=12.04, p<0.001$.

\section{The Impact of Demographic and Neonatal Risk Factors}

on EF Of the demographic factors gender and maternal education, which were entered in the first block, gender was not associated with any of the EF dependent variables. Maternal education explained $12 \%$ of the variance $\left(R^{2}=\right.$ $0.12 ; F(2,47)=3.26, p<0.05)$ in efficiency on the Shape School inhibition condition $(\beta=0.31, p<0.05)$, and did not predict performance on any of the other EF dependent variables (variance explained $\leq 4 \%$, all $p \mathrm{~s}>0.25$ ). Gestational age, entered in the second block, explained $12 \%$ of the variance $\left(R^{2}=0.08 ; F(1,46)=4.12, p<0.05\right)$ in performance on the OCTC $(\beta=0.29, p<0.05)$, however was not predictive for the other EF dependent variables, (variance explained $<6 \%$, all $p \mathrm{~s}>0.09$ ). The NBRS total score, which was entered in the third or final block, did not predict performance on any of the EF measures (variance explained $\leq 7 \%$, all $p \mathrm{~s}>0.08$ ).

\section{Discussion}

This study compared test performance of 50 very preterm children at early school age to that of 50 age-matched controls on a comprehensive EF battery. The findings demonstrated that very preterm children with average IQ performed significantly poorer than the healthy term born children on EF tests of inhibition, switching, working memory, verbal fluency, and concept generation. Group differences were not attributable to maternal education, and 
Table 4 Rates of Executive Function Impairments in the Very Preterm and Control Group

\begin{tabular}{lccc}
\hline Dependent Variables & $\begin{array}{l}\text { Very Preterm } \\
\mathrm{n}(\%)\end{array}$ & $\begin{array}{l}\text { Control } \\
\mathrm{n}(\%)\end{array}$ & $\chi^{2}$ \\
\hline SS Control time in ms & $23(46)$ & $7(14)$ & $12.90^{* * *}$ \\
SS Inhibition total correct & $14(28)$ & $12(24)$ & .21 \\
SS Inhibition efficiency & $0(0)$ & $2(4)$ & 2.04 \\
SS Switching total correct & $19(38)$ & $8(16)$ & $6.14^{* *}$ \\
SS Switching efficiency & $12(24)$ & $3(6)$ & $6.35^{*}$ \\
Go/NoGo total correct & $11(22)$ & $4(8)$ & $3.84^{*}$ \\
Go/NoGo efficiency & $18(26)$ & $6(12)$ & $7.90^{* * *}$ \\
DN Exp total correct & $31(62)$ & $21(42)$ & $4.01^{*}$ \\
DN Exp efficiency & $33(66)$ & $10(20)$ & $21.58^{* * *}$ \\
VF total correct & $12(24)$ & $8(16)$ & 1.00 \\
WS total correct forwards & $23(46)$ & $19(38)$ & .66 \\
WS total correct backwards & $18(36)$ & $1(2)$ & $18.78^{* * *}$ \\
OCTC total points & $18(36)$ & $5(10)$ & $9.54^{* *}$ \\
\hline
\end{tabular}

Definition of an impairment is given in the text.

DN Exp $=$ Day-Night task experimental condition, OCTC $=$ Object Classification Task for Children, SS Control $=$ Shape School control condition, SS Inhibition $=$ Shape School inhibition condition, SS Switching $=$ Shape School switching condition, $\mathrm{VF}=$ Verbal Fluency, WS $=$ Word Span.

${ }^{*} p<0.05$.

$* * p<0.01$.

$* * * p<0.001$.

remained significant when very preterm children with neurosensory impairments were excluded from the analyses. In addition, very preterm children displayed significant higher rates of impairments in processing speed, inhibition, switching, working memory, and concept generation, than the controls.

We examined the impact of processing speed on inhibition and switching. Very preterm children demonstrated poorer inhibitory control than the controls on the Go/NoGo task and the Day-Night task. Group differences remained significant after controlling for processing speed, which suggests that very preterm children exhibit a deficit in inhibitory control in addition to slower processing speed. These findings converge with the findings of Christ et al. (2003). Group differences for switching, however, became nonsignificant after covarying for processing speed, which suggests that switching difficulties in very preterm children might be explained by slow processing speed. Different cognitive processes are involved in switching, i.e., holding the switching rule in mind (working memory), inhibiting the incorrect response (inhibition), and switching response set (Diamond 2002). The developmental pathways of these processes differ, and inhibition is one of the first EFs to emerge (Barkley 1997; Brocki and Bohlin 2004). At early school age switching is still immature (Anderson et al. 2000a, b). Performing immature cognitive processes heavily appeals to speed (Isquith et al. 2005), and as response time improves significantly during childhood (Isquith et al. 2005), it seems that our results point to the fact that switching processes in very preterm children are so immature that these childrens' performance in switching tasks is dominated by processing speed.

The very preterm group obtained a mean IQ within the average range, which however was significantly lower than the mean IQ of the control group. It should be noted that the high average mean IQ of the control group might be associated with the high level of maternal education, though the groups did not differ significantly in level of maternal education. Group differences between the very preterm children and the controls could not be explained by differences in IQ. Our results are in line with research stating that EF is related to, yet distinct from IQ (Friedman et al. 2006). Among studies into EF in very preterm children, there is substantial variation in whether poor EF in these children is independent of IQ (e.g., Bayless and Stevenson 2007; Bohm et al. 2004; Edgin et al. 2008; Marlow et al. 2007). Divergent findings across these studies might be related to differences in measures employed. For example, abbreviated IQ measures may not be as reliable as more comprehensive IQ measures, as extreme scores have far greater influence. In addition, some IQ measures have a greater focus on fluid intelligence in contrast to crystallized intelligence, than others, which is likely to result in higher correlations with EF (Blair 2006). In our study three of the four subtests employed to estimate IQ had a fluid component (Similarities, Picture Arrangement and Block Design; Blair 2006). IQ is suggested to mostly influence more complex functions that require a greater degree of conceptual problem-solving ability and higher levels of cognitive efficiency (Blair 2006; Seidenberg et al. 1983), which was supported by our findings showing a substantial overlap between IQ and measures of concept generation (OCTC), working memory, and (verbal) inhibition (Word Span backwards, and Day-Night task). In conclusion, to obtain a thorough understanding of very preterm childrens' neurocognitive difficulties, both EF and IQ should be measured, since EF and IQ are related yet distinct concepts.

In the present study, we investigated the relationship between demographic and neonatal risk factors and EF. We found that gender was not associated with EF. Although some studies with normally developing children found gender differences in performance on EF tasks (Anderson et al. 2000a, b; Krikorian and Bartok 1998), most research agrees on that boys and girls show similar development of EF (e.g., Welsh et al. 1991). In line with previous research (Ardila et al. 2005), maternal education was, though marginally, associated with EF. This finding suggests a 
modest role for stimulating environmental aspects to improve EF, though more specific environmental factors, such as family functioning, parenting style, and the presence of resources and opportunities, might even have a greater contribution (Aylward 1992). However, these factors were not targeted in the present study, and our sample size limited the inclusion of more than 5 predictors in the analyses. Creating a stimulating environment yet early in development should focus on parent instruction to enhance parent-child interaction (Als et al. 2003; Aylward 1992). Other environmental focused intervention techniques that have been shown to be successful in children with executive dysfunction include computer guided behavioral training (Dowsett and Livesey 2000; Klingberg et al. 2005; Marlowe 2000).

In our study, the degree of neonatal illness was not associated with poor performance on the EF tasks, although Luciana et al. (1999) previously demonstrated that a high level of neonatal illness was associated with poor working memory. Our findings might be related to the fact that in our study the incidence of neonatal medical events such as infections or IVH was fairly low. Paralleling previous findings (Saavalainen et al. 2007; Taylor et al. 2004a, b), we did find that gestational age was related to $\mathrm{EF}$, in particular to concept generation. It might not be neonatal illness associated with preterm birth in particular that results in deficits in EF, but rather the preterm birth itself that constitutes the risk for EF deficits (Taylor et al. 2004a, b).

Strengths of the study concern the sample, which comprises consecutive admissions, comparison to an agematched control group, assessment at early school age, and statistical control for both IQ and speed of processing in the analyses. A limitation is that reliability and validity of our battery of neurocognitive measures have not been fully assessed for all measures. However, the use of experimental measures tapping into a comprehensive range of $\mathrm{EF}$ abilities with differing levels of complexity helps to chart the nature of the neurocognitive difficulties in very preterm children under various levels of executive demand. Some of our tasks have been specifically developed to capture neurocognitive processes underlying task performance (e.g., Espy et al. 2006). In addition, verbal fluency and Go/NoGo tasks, as employed in the present study, have been found fruitful in elucidating functioning of the corpus callosum, cerebellum, cingulate gyrus, and prefrontal cortex in very preterm children and adolescents (Lawrence et al. 2009; Narberhaus et al. 2008; Nosarti et al. 2004). Future studies, using techniques such as functional imaging (fMRI) or diffusion tensor imaging (DTI), should be conducted to cast more light on how EF deficits in these children are related to white and grey matter pathology.

In conclusion, our findings add to the relatively small but rapidly growing literature on early school-aged very preterm children, and demonstrate poor performance on EF measures related to very preterm birth, which could not be explained by IQ. Furthermore, it shows that speed of processing is marginally related to EF in very preterm children. The results show that very preterm children are at high risk for EF impairments, beside the risk for adverse outcome at later ages already constituted by lower IQ scores and slow speed of processing (McDermott et al. 2006). An unresolved issue is whether EF deficits in very preterm children reflect a maturational lag or a permanent impairment. This question calls for a longitudinal approach. Nevertheless, the EF deficits observed may have important implications for their later academic and behavioral functioning (Bull and Scerif 2001; Martinussen and Tannock 2006; Pennington and Ozonoff 1996). Many follow-up studies document the outcomes of very preterm children in terms of neurosensory handicaps and IQ scores. However, of significant concern is the 'trend of worsening outcome' in the non-disabled very preterm survivors (Aylward 2005). An important role in this issue may be played by subtle deficits in cognitive processes such as EF which hamper the ability to function in an increasingly complex and demanding environment (Salt and Redshaw 2006). Our findings underline the need in neonatal followup care to extend the regular use of IQ assessments with the assessments of EFs and processing speed.

Disclosure The authors have no financial relationships to disclose.

Open Access This article is distributed under the terms of the Creative Commons Attribution Noncommercial License which permits any noncommercial use, distribution, and reproduction in any medium, provided the original author(s) and source are credited.

\section{References}

Allin, M., Walshe, M., Fern, A., Nosarti, C., Cuddy, M., Rifkin, L., et al. (2008). Cognitive maturation in preterm and term born adolescents. Journal of Neurology, Neurosurgery, and Psychiatry, 79, 381-386. doi:10.1136/jnnp.2006.110858.

Als, H., Gilkerson, L., Duffy, F. H., McAnulty, G. B., Buehler, D. M., Vandenberg, K., et al. (2003). A three-center, randomized, controlled trial of individualized developmental care for very low birth weight preterm infants: medical, neurodevelopmental, parenting, and caregiving effects. Journal of Developmental and Behavioral Pediatrics, 24, 399-408. doi:10.1097/00004703200312000-00001.

Altemeier, L., Jones, J., Abbott, R. D., \& Berninger, V. W. (2006). Executive functions in becoming writing readers and reading writers: note taking and report writing in third and fifth graders. Developmental Neuropsychology, 29, 161-173. doi:10.1207/ s15326942dn2901_8.

Anderson, P. J., \& Doyle, L. W. (2003). Neurobehavioral outcomes of school-age children born extremely low birth weight or very preterm in the 1990s. Journal of the American Medical Association, 289, 3264-3272. doi:10.1001/jama.289.24.3264. 
Anderson, P. J., \& Doyle, L. W. (2004). Executive functioning in school-aged children who were born very preterm or with extremely low birth weight in the 1990s. Pediatrics, 114, 5057. doi:10.1542/peds.114.1.50.

Anderson, P. J., Anderson, V., Northam, E., \& Taylor, H. (2000a). Standardization of the Contingency Naming Test for school-aged children: A new measure of reactive flexibility. Clinical Neuropsychological Assessment, 1, 247-273.

Anderson, S. W., Damasio, H., Tranel, D., \& Damasio, A. R. (2000b). Long-term sequelae of prefrontal cortex damage acquired in early childhood. Developmental Neuropsychology, 18, 281-296. doi:10.1207/S1532694202Anderson.

Anjari, M., Srinivasan, L., Allsop, J. M., Hajnal, J. V., Rutherford, M. A., Edwards, A. D., et al. (2007). Diffusion tensor imaging with tract-based spatial statistics reveals local white matter abnormalities in preterm infants. NeuroImage, 35, 1021-1027. doi:10.1016/j.neuroimage.2007.01.035.

Ardila, A., Pineda, D., \& Rosselli, M. (2000). Correlation between intelligence test scores and executive function measures. Archives of Clinical Neuropsychology, 15, 31-36.

Ardila, A., Rosselli, M., Matute, E., \& Guajardo, S. (2005). The influence of the parents' educational level on the development of executive functions. Developmental Neuropsychology, 28, 539560. doi:10.1207/s15326942dn2801 5 .

Arffa, S. (2007). The relationship of intelligence to executive function and non-executive function measures in a sample of average, above average, and gifted youth. Archives of Clinical Neuropsychology, 22, 969-978. doi:10.1016/j.acn.2007.08.001.

Aylward, G. P. (1992). The relationship between environmental risk and developmental outcome. Journal of Developmental and Behavioral Pediatrics, 13, 222-229. doi:10.1097/00004703-19920600000013.

Aylward, G. P. (2005). Neurodevelopmental outcomes of infants born prematurely. Journal of Developmental and Behavioral Pediatrics, 26, 427-440. doi:10.1097/00004703-200512000-00008.

Barkley, R. A. (1997). Behavioral inhibition, sustained attention, and executive functions: constructing a unifying theory of ADHD. Psychological Bulletin, 121, 65-94. doi:10.1037/0033-2909. 121.1.65.

Barnes, M. A., \& Dennis, M. (1998). Discourse after Early-Onset Hydrocephalus: Core Deficits in Children of Average Intelligence. Brain and Language, 61, 309-334. doi:10.1006/ brln.1998.1843.

Bayless, S., \& Stevenson, J. (2007). Executive functions in school-age children born very prematurely. Early Human Development, 83, 247-254. doi:10.1016/j.earlhumdev.2006.05.021.

Bhutta, A. T., Cleves, M. A., Casey, P. H., Cradock, M. M., \& Anand, K. J. (2002). Cognitive and behavioral outcomes of school-aged children who were born preterm: a meta-analysis. Journal of the American Medical Association, 288, 728-737. doi:10.1001/jama.288.6.728.

Blair, C. (2006). How similar are fluid cognition and general intelligence? A developmental neuroscience perspective on fluid cognition as an aspect of human cognitive ability. The Behavioral and Brain Sciences, 29, 109-125. discussion 125-160.

Bohm, B., Smedler, A. C., \& Forssberg, H. (2004). Impulse control, working memory and other executive functions in preterm children when starting school. Acta Paediatrica (Oslo, Norway), 93, 1363-1371. doi:10.1080/08035250410021379.

Botting, N., Powls, A., Cooke, R. W., \& Marlow, N. (1997). Attention deficit hyperactivity disorders and other psychiatric outcomes in very low birthweight children at 12 years. Journal of Child Psychology and Psychiatry, and Allied Disciplines, 38, 931-941. doi:10.1111/j.1469-7610.1997.tb01612.x.

Brazy, J. E., Eckerman, C. O., Oehler, J. M., Goldstein, R. F., \& O'Rand, A. M. L. (1991). Nursery Neurobiologic Risk Score: important factor in predicting outcome in very low birth weight infants. The Journal of Pediatrics, 118, 783-792. doi:10.1016/ S0022-3476(05)80047-2.

Brocki, K. C., \& Bohlin, G. (2004). Executive functions in children aged 6 to 13: a dimensional and developmental study. Developmental Neuropsychology, 26, 571-593. doi:10.1207/s15326942dn2602_3.

Brosnan, M., Demetre, J., Hamill, S., Robson, K., Shepherd, H., \& Cody, G. (2002). Executive functioning in adults and children with developmental dyslexia. Neuropsychologia, 40, 2144-2155. doi:10.1016/S0028-3932(02)00046-5.

Bull, R., \& Scerif, G. (2001). Executive functioning as a predictor of children's mathematics ability: inhibition, switching, and working memory. Developmental Neuropsychology, 19, 273-293. doi:10.1207/S15326942DN1903 3.

Casey, B. J., Castellanos, F. X., \& Geìdd, J. N. (1997). Implication of right frontostriatal circuitry in response inhibition and attention deficit/hyperactivity disorder. Journal of the American Academy of Child and Adolescent Psychiatry, 36, 374-383. doi:10.1097/ 00004583-199703000-00016.

Central Office of Statistics (2004). Centraal bureau voor de statistiek. Standaard onderwijsindeling 2003. Voorburg/Heerlen.

Charlton, R. A., Barrick, T. R., McIntyre, D. J., Shen, Y., O'Sullivan, M., Howe, F. A., et al. (2006). White matter damage on diffusion tensor imaging correlates with age-related cognitive decline. Neurology, 66, 217-222. doi:10.1212/01.wnl.0000194256.15247.83.

Christ, S. E., White, D. A., Brunstrom, J. E., \& Abrams, R. A. (2003). Inhibitory control following perinatal brain injury. Neuropsychology, 17, 171-178. doi:10.1037/0894-4105.17.1.171.

Cohen, J. (1992). A Power Primer. Psychological Bulletin, 112, 155159. doi:10.1037/0033-2909.112.1.155.

Demetriou, A., Christou, C., Spanoudis, G., \& Platsidou, M. (2002). The development of mental processing: efficiency, working memory, and thinking. Monographs of the Society for Research in Child Development, 67, i-viii, 1-155. discussion 156.

Diamond, A. (2002). Normal development of prefrontal cortex from birth to young adulthood: cognitive functions, anatomy, and biochemistry. In D. T. Stuss \& R. T. Knight (Eds.), Principles of frontal lobe function (pp. 504-527). New York: Oxford University Press.

Diamond, A., Kirkham, N., \& Amso, D. (2002). Conditions under which young children can hold two rules in mind and inhibit a prepotent response. Developmental Psychology, 38, 352-362. doi:10.1037/0012-1649.38.3.352.

Dowsett, S. M., \& Livesey, D. J. (2000). The development of inhibitory control in preschool children: effects of "executive skills" training. Developmental Psychobiology, 36, 161-174. doi:10.1002/(SICI) 1098-2302(200003)36:2<161::AIDDEV7>3.0.CO;2-0.

Drewe, E. A. (1975). Go - no go learning after frontal lobe lesions in humans. Cortex, 11, 8-16.

Duncan, J., Emslie, H., Williams, P., Johnson, R., \& Freer, C. (1996). Intelligence and the frontal lobe: the organization of goal-directed behavior. Cognitive Psychology, 30, 257-303. doi:10.1006/cogp. 1996.0008.

Edgin, J. O., Inder, T. E., Anderson, P. J., Hood, K. M., Clark, C. A. C., \& Woodward, L. J. (2008). Executive functioning in preschool children born very preterm: Relationship with early white matter pathology. Journal of the International Neuropsychological Society, 14, 90-101. doi:10.1017/S1355617708080053.

Espy, K. A. (1997). The Shape School: Assessing executive function in preschool children. Developmental Neuropsychology, 13, 495-499.

Espy, K. A., Bull, R., Martin, J., \& Stroup, W. (2006). Measuring the development of executive control with the shape school. Psychological Assessment, 18, 373-381. doi:10.1037/1040-3590.18.4.373.

Friedman, N. P., Miyake, A., Corley, R. P., Young, S. E., Defries, J. C., \& Hewitt, J. K. (2006). Not all executive functions are related to intelligence. Psychological Science, 17, 172-179. doi:10.1111/ j.1467-9280.2006.01681.x. 
Friedman, N. P., Haberstick, B. C., Willcutt, E. G., Miyake, A., Young, S. E., Corley, R. P., et al. (2007). Greater attention problems during childhood predict poorer executive functioning in late adolescence. Psychological Science, 18, 893-900. doi:10.1111/j.1467-9280.2007.01997.x.

Gerstadt, C. L., Hong, Y. J., \& Diamond, A. (1994). The relationship between cognition and action: performance of children $31 / 2-$ 7 years old on a Stroop-like day-night test. Cognition, 53, 129153. doi:10.1016/0010-0277(94)90068-X.

Groth-Marnat, G. (1997). Handbook of psychological assessment (3rd ed.). New York: Wiley.

Harvey, J. M., O'Callaghan, M. J., \& Mohay, H. (1999). Executive function of children with extremely low birthweight: a case control study. Developmental Medicine and Child Neurology, 41, 292-297. doi:10.1017/S0012162299000663.

Hille, E. T., den Ouden, A. L., Bauer, L., van den Oudenrijn, C., Brand, R., \& Verloove-Vanhorick, S. P. (1994). School performance at 9 years of age in very premature and very low birth weight infants: perinatal risk factors and predictors at 5 years of age. Collaborative Project on Preterm and Small for Gestational Age (POPS) Infants in The Netherlands. Journal of Pediatrics, $125,426-434$.

Isquith, P. K., Crawford, J. S., Espy, K. A., \& Gioia, G. A. (2005). Assessment of executive function in preschool-aged children. Mental Retardation and Developmental Disabilities Research Reviews, 11, 209-215. doi:10.1002/mrdd.20075.

Kail, R. (1991). Developmental change in speed of processing during childhood and adolescence. Psychological Bulletin, 109, 490501. doi:10.1037/0033-2909.109.3.490.

Klebanov, P. K., Brooks-Gunn, J., \& McCormick, M. C. (1994). School achievement and failure in very low birth weight children. Journal of Developmental and Behavioral Pediatrics, 15, 248256. doi:10.1097/00004703-199408000-00005.

Klingberg, T., Fernell, E., Olesen, P. J., Johnson, M., Gustafsson, P., Dahlstrom, K., et al. (2005). Computerized training of working memory in children with ADHD-a randomized, controlled trial. Journal of the American Academy of Child and Adolescent Psychiatry, 44, 177-186. doi:10.1097/00004583-200502000-00010.

Krikorian, R., \& Bartok, J. (1998). Developmental data for the Porteus Maze Test. The Clinical Neuropsychologist, 12, 305-310. doi:10.1076/clin.12.3.305.1984.

Kulseng, S., Jennekens-Schinkel, A., Naess, P., Romundstad, P., Indredavik, M., Vik, T., et al. (2006). Very-low-birthweight and term small-for-gestational-age adolescents: attention revisited. Acta Paediatrica (Oslo, Norway), 95, 224-230.

Lawrence, E. J., Rubia, K., Murray, R. M., McGuire, P. K., Walshe, M., Allin, M., et al. (2009). The neural basis of response inhibition and attention allocation as mediated by gestational age. Human Brain Mapping, 30, 1038-1050. doi:10.1002/hbm.20564.

Lezak, M. D., Howieson, D. W., \& Loring, D. W. (2004). Neuropsychological assessment (4th ed.). New York: Oxford University Press.

Luciana, M., Lindeke, L., Georgieff, M., Mills, M., \& Nelson, C. A. (1999). Neurobehavioral evidence for working-memory deficits in school-aged children with histories of prematurity. Developmental Medicine and Child Neurology, 41, 521-533. doi:10.1017/S0012162299001140.

Marlow, N., Hennessy, E. M., Bracewell, M. A., \& Wolke, D. (2007). Motor and executive function at 6 years of age after extremely preterm birth. Pediatrics, 120, 793-804. doi:10.1542/peds.2007-0440.

Marlowe, W. B. (2000). An intervention for children with disorders of executive functions. Developmental Neuropsychology, 18, 445454. doi:10.1207/S1532694209Marlowe.

Martinussen, R., \& Tannock, R. (2006). Working memory impairments in children with attention-deficit hyperactivity disorder with and without comorbid language learning disorders. Journal of Clinical and Experimental Neuropsychology, 28, 1073-1094. doi:10.1080/13803390500205700.

Matthews, A., Ellis, A. E., \& Nelson, C. A. (1996). Development of preterm and full-term infant ability on $\mathrm{AB}$, recall memory, transparent barrier detour, and means-end tasks. Child Development, 67, 2658-2676. doi:10.2307/1131745.

Mazzocco, M. M., \& Kover, S. T. (2007). A longitudinal assessment of executive function skills and their association with math performance. Child Neuropsychology, 13, 18-45. doi:10.1080/ 09297040600611346.

McDermott, P. A., Goldberg, M. M., Watkins, M. W., Stanley, J. L., \& Glutting, J. J. (2006). A nationwide epidemiologic modeling study of LD: risk, protection, and unintended impact. Journal of Learning Disabilities, 39, 230-251. doi:10.1177/00222194060390030401.

Narberhaus, A., Segarra, D., Caldu, X., Gimenez, M., Pueyo, R., Botet, F., et al. (2008). Corpus callosum and prefrontal functions in adolescents with history of very preterm birth. Neuropsychologia, 46, 111-116. doi:10.1016/j.neuropsychologia.2007.08.004.

Nigg, J. T. (2005). Neuropsychologic theory and findings in attentiondeficit/hyperactivity disorder: the state of the field and salient challenges for the coming decade. Biological Psychiatry, 57, 1424-1435. doi:10.1016/j.biopsych.2004.11.011.

Nigg, J. T., Blaskey, L. G., Huang-Pollock, C. L., \& Rappley, M. D. (2002). Neuropsychological executive functions and DSM-IV ADHD subtypes. Journal of the American Academy of Child and Adolescent Psychiatry, 41, 59-66. doi:10.1097/00004583-200201000-00012.

Nosarti, C., Giouroukou, E., Micali, N., Rifkin, L., Morris, R. G., \& Murray, R. M. (2007). Impaired executive functioning in young adults born very preterm. Journal of the International Neuropsychological Society, 13, 571-581. doi:10.1017/S1355617707070725.

Nosarti, C., Rushe, T. M., Woodruff, P. W., Stewart, A. L., Rifkin, L., \& Murray, R. M. (2004). Corpus callosum size and very preterm birth: relationship to neuropsychological outcome. Brain, 127, 2080-2089.

Pennington, B. F., \& Ozonoff, S. (1996). Executive functions and developmental psychopathology. Journal of Child Psychology and Psychiatry, and Allied Disciplines, 37, 51-87. doi:10.1111/ j.1469-7610.1996.tb01380.x.

Picton, T. W., Stuss, D. T., Alexander, M. P., Shallice, T., Binns, M. A., \& Gillingham, S. (2007). Effects of Focal Frontal Lesions on Response Inhibition. Cerebral Cortex (New York, N.Y.), 4, 826-838.

Powell, K. B., \& Voeller, K. K. (2004). Prefrontal executive function syndromes in children. Journal of Child Neurology, 19, 785-797.

Raaijmakers, M. A., Smidts, D. P., Sergeant, J. A., Maassen, G. H., Posthumus, J. A., van Engeland, H., et al. (2008). Executive functions in preschool children with aggressive behavior: impairments in inhibitory control. Journal of Abnormal Child Psychology, 36, 1097-1107. doi:10.1007/s10802-008-9235-7.

Rose, S. A., Feldman, J. F., \& Jankowski, J. J. (2002). Processing speed in the 1st year of life: a longitudinal study of preterm and full-term infants. Developmental Psychology, 38, 895-902. doi:10.1037/0012-1649.38.6.895.

Rucklidge, J. J., \& Tannock, R. (2002). Neuropsychological profiles of adolescents with ADHD: effects of reading difficulties and gender. Journal of Child Psychology and Psychiatry, and Allied Disciplines, 43, 988-1003. doi:10.1111/1469-7610.00227.

Rushe, T. M., Rifkin, L., Stewart, A. L., Townsend, J. P., Roth, S. C., Wyatt, J. S., et al. (2001). Neuropsychological outcome at adolescence of very preterm birth and its relation to brain structure. Developmental Medicine and Child Neurology, 43, 226-233. doi:10.1017/S0012162201000433.

Russell, J. (1997). Autism as an executive disorder. Oxford: Oxford University Press.

Saavalainen, P., Luoma, L., Bowler, D., Maatta, S., Kiviniemi, V., Laukkanen, E., et al. (2007). Spatial span in very prematurely born adolescents. Developmental Neuropsychology, 32, 769-785. 
Salt, A., \& Redshaw, M. (2006). Neurodevelopmental follow-up after preterm birth: follow up after 2 years. Early Human Development, 82, 185-197. doi:10.1016/j. earlhumdev.2005.12.015.

Salthouse, T. A., Fristoe, N., McGuthry, K. E., \& Hambrick, D. Z. (1998). Relation of task switching to speed, age, and fluid intelligence. Psychology and Aging, 13, 445-461. doi:10.1037/ 0882-7974.13.3.445.

Sattler, J. M. (1992). Assessment of children, WISC-III and WPPSI-R supplement. San Diego, California: Publisher, Inc.

Seidenberg, M., Giordani, B., Berent, S., \& Boll, T. J. (1983). IQ level and performance on the Halstead-Reitan Neuropsychological Test Battery for Older Children. Journal of Consulting and Clinical Psychology, 51, 406-413. doi:10.1037/0022-006X.51.3.406.

Sergeant, J. (2000). The cognitive-energetic model: an empirical approach to attention-deficit hyperactivity disorder. Neuroscience and Biobehavioral Reviews, 24, 7-12. doi:10.1016/S0149-7634 (99)00060-3.

Shum, D., Neulinger, K., O’Callaghan, M., \& Mohay, H. (2008). Attentional problems in children born very preterm or with extremely low birth weight at 7-9 years. Archives of Clinical Neuropsychology, 23, 103-112. doi:10.1016/j.acn.2007.08.006.

Simpson, A., \& Riggs, K. J. (2005). Factors responsible for performance on the day-night task: response set or semantics? Developmental Science, 8, 360-371. doi:10.1111/j.1467-7687.2005.00424.x.

Smidts, D. P. (2003). Development of executive processes in early childhood. Melbourne, Victoria, Australia: University of Melbourne.

Smidts, D. P., \& Groot, P. (2005). The shape school (Computer program) [E-Prime computer Software]. Amsterdam: Vrije Universiteit Amsterdam.

Smidts, D. P., Jacobs, R., \& Anderson, V. (2004). The Object Classification Task for Children (OCTC): a measure of concept generation and mental flexibility in early childhood. Developmental Neuropsychology, 26, 385-401. doi:10.1207/s15326942dn2601_2.

Stjernqvist, K., \& Svenningsen, N. W. (1999). Ten-year follow-up of children born before 29 gestational weeks: health, cognitive development, behaviour and school achievement. Acta Paediatrica (Oslo, Norway), 88, 557-562. doi:10.1080/0803525.

Surveillance of Cerebral Palsy in Europe (SCPE) (2000). Surveillance of cerebral palsy in Europe: a collaboration of cerebral palsy surveys and registers. Developmental Medicine and Child Neurology, 42, 816-824.

Tabachnick, B. G., \& Fidell, L. S. (2001). Using multivariate statistics (4th ed.). Needham Heights, MA: Allyn \& Bacon.

Taylor, H. G., Minich, N., Bangert, B., Filipek, P. A., \& Hack, M. (2004a). Long-term neuropsychological outcomes of very low birth weight: associations with early risks for periventricular brain insults. Journal of the International Neuropsychological Society, 10, 987-1004.

Taylor, H. G., Minich, N. M., Klein, N., \& Hack, M. (2004b). Longitudinal outcomes of very low birth weight: neuropsychological findings. Journal of the International Neuropsychological Society, 10, 149-163.

Taylor, H. G., Klein, N., Drotar, D., Schluchter, M., \& Hack, M. (2006). Consequences and risks of \&1t;1000-g birth weight for neuropsychological skills, achievement, and adaptive functioning. Journal of Developmental and Behavioral Pediatrics, 27, 459-469. doi:10.1097/00004703-200612000-00002.

Usher, R., \& McLean, F. (1969). Intrauterine growth of live-born Caucasian infants at sea level: standards obtained from measurements in 7 dimensions of infants born between 25 and 44 weeks of gestation. Journal of Pediatrics, 74, 901-910.

van der Schoot, M., Licht, R., Horsley, T. M., \& Sergeant, J. A. (2000). Inhibitory deficits in reading disability depend on subtype: guessers but not spellers. Neuropsychology Development and Cognition Section C in Child Neuropsychology, 6, 297-312.

Vander Steene, G., \& Bos, A. (1997). WPPSI-R: Wechsler preschool and primary scale of intelligence (Dutch-Flemish version). Lisse: Swets \& Zeitlinger.

Wechsler, D. (1997). Wechsler preschool and primary scale of intelligence-revised (WPPSI-R). San Antonio, TX: The Psychological Corporation.

Weisglas-Kuperus, N., Baerts, W., Smrkovsky, M., \& Sauer, P. J. (1993). Effects of biological and social factors on the cognitive development of very low birth weight children. Pediatrics, 92, 658-665.

Welsh, M. C., Pennington, B. F., \& Groisser, D. B. (1991). A normative-developmental study of executive function: A window on prefrontal function in children. Developmental Neuropsychology, 7, 131-149.

Whitaker, A. H., Van Rossem, R., Feldman, J. F., Schonfeld, I. S., Pinto-Martin, J. A., Tore, C., et al. (1997). Psychiatric outcomes in low-birth-weight children at age 6 years: relation to neonatal cranial ultrasound abnormalities. Archives of General Psychiatry, $54,847-856$.

Wolke, D., \& Meyer, R. (1999). Cognitive status, language attainment, and prereading skills of 6-year-old very preterm children and their peers: the Bavarian Longitudinal Study. Developmental Medicine and Child Neurology, 41, 94-109. doi:10.1017/ S0012162299000201.

Wood, N. S., Marlow, N., Costeloe, K., Gibson, A. T., \& Wilkinson, A. R. (2000). Neurologic and developmental disability after extremely preterm birth. EPICure Study Groups. The New England Journal of Medicine, 343, 378-384. doi:10.1056/NEJM200008103430601. 